(indoleacetic acid) is the auxin of importance in pineapple flowering.

Pineapple Research Institute of Hawair, Honolulu, Hawait

\section{LITERATURE CITED}

Bonner, J., and J. Liverman. 1953. Hormonal control of flower initiation. In Growth and differentiation in plants, p. 299-300. Iowa State College Press. Ames.

Clark, H. E. and K. R. Kerns. 1942. Control of flowering with phytohormones. Science 95:536-537.

Cooper, W. C. And P. C. REece. 1942. Induced flowering of pineapples under Florida conditions. Proc. Florida State Hort. Soc. 54 (1941):132-138.

Foster, R. J., D. H. McRae, and J. Bonner. 1952. Auxininduced growth inhibition a natural consequence of two-point attachment. Proc. National Acad. Sci. (U.S.) 38:1014-1022.

Gordon, S. A., and F. S. Nieva. 1949. Biosynthesis of auxin in the vegetative pineapple. I., II. Arch. Biochem. and Biophys. 20:356-385.
Gowing, D. P., AND R. W. LeEPER. 1955. Induction of flowering in pineapple by beta-hydroxyethylhydrazine. Science $122: 1267$.

Leopold, A. C. 1955. In Auxins and plant growth, pp. 258260. Univ. California Press. Los Angeles.

- And K. V. Thimann. 1949. The effect of auxin on flower initiation. Amer. Jour. Bot. 36:342-347.

Linford, M. B. 1933. Fruit quality studies. II. Eye number and eye weight. Pineapple Quart. 3:185-188.

ThImann, K. V. 1937. On the nature of inhibitions caused by auxin. Amer. Jour. Bot. 24:407-412.

Skoog, F., And C. Tsur. 1951. Growth substances and the formation of buds in plant tissues. In Plant growth substances, pp. 263-285. Univ. Wisconsin Press. Madison.

VAN Overbeek, J. 1951. Use of growth substances in tropical agriculture. In Plant growth substances, p. 225 244. Univ. Wisconsin Press. Madison. , E. S. de Vásquez, and S. A. Gordon. 1947. Free and bound auxin in the vegetative pineapple plant. Amer. Jour. Bot. 34:266-270.

\title{
STUDIES IN THE HIPPOCASTANACEAE II. INFLORESCENCE STRUCTURE AND DISTRIBUTION OF PERFECT FLOWERS ${ }^{1}$
}

\author{
James W. Hardin
}

In ConJunction with a detailed study of the phylogeny and systematics of the American species of the Hippocastanaceae, two questions concerning the inflorescences have arisen. First, just what basic type of inflorescence is represented and what changes in this basic type cause the conspicuous variations in size and shape? Second, what is the distribution of perfect flowers within an inflorescence?

INFLORESCENCE STRUCTURE.-A brief look at the literature concerning the inflorescences of the Hippocastanaceae, or, for that matter, inflorescences in general, illustrates how thoroughly confused terminology can become when early misinterpretations are wrongly "corrected" or reproduced over and over in textbooks and manuals. The inflorescence of Aesculus has been described as a raceme, panicle, or a thyrse with lateral helicoid or scorpioid cymes depending upon which author one follows. Thanks to the recent studies by Rickett $(1944,1955)$ the terminology of inflorescences is now more understandable and usable. I am therefore following the proposals of his latest paper (1955) for the terms used here.

The inflorescence type of the Latin American genus Billia is a diffuse terminal panicle (fig. l-3). The central axis exhibits opposite branching; the lateral branches are paniculate, bearing dichasia at

${ }^{1}$ Received for publication December 1, 1955. I am deeply grateful to Dr. Warren H. Wagner, Jr., Department of Botany, University of Michigan, for his real interest and constructive criticism during the preparation of the manuscript. the ends and along the sides; they are in part monopodial. Each lateral branch from the central axis is subtended by a bract and at the node of each successive branching there is a pair of small subtending bracteoles. Deviations from this type of inflorescence result in a wide variation in size, shape, and general aspect.

The illustrations of Billia inflorescences (fig. . 1-3) show branches of only one plane for sake of clarity. The branches of the central axis, however, are actually decussate, i.e., succeeding pairs are turned more or less $90^{\circ}$.

Very commonly in Billia columbiana Pl. \& Lind. the inflorescence is very large, diffuse, and leafy at the base, as illustrated in fig. 1. The lowermost branches of this inflorescence are subtended by unmodified leaves rather than the caducous bracts that are found at the upper nodes. The first internodes of these lowest branches are often very long, producing a very broad and nearly flat-topped inflorescence.

Within the lateral branches, abortion of the central or lateral member of a dichasial cluster, or both, has resulted in an apparent dichotomy or monopodium in many positions throughout the inflorescence. The lost member in either situation is usually abortive and caducous. At each node there is always found the subtending bracteole of the abortive branch and usually a scar left by the abortive and caducous member. The occurrence of these abortive or little developed branches sug. gests various degrees of suppression of branches of monopodial or dichasial axes. 


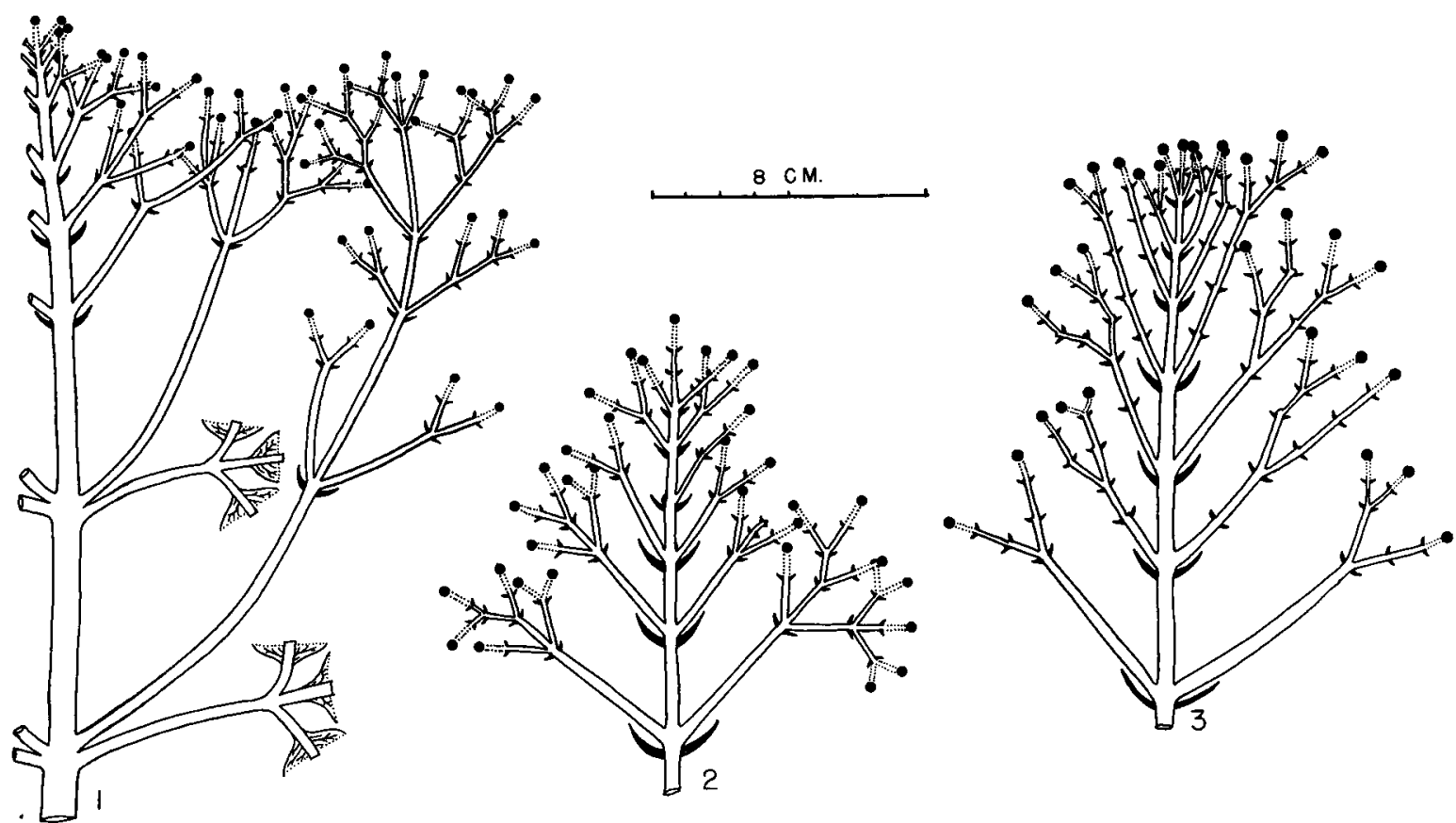

Fig. 1-3. Diagrammatic representation of the inflorescences of Billia.-Fig. 1. B. columbiana Pl. \& Lind.-Fig. 2, 3. B. hippocastanum Peyr.

In Billia hippocastanum Peyr. (fig. 2,3) the subtending leaves have been replaced by small bracts and there is more tendency toward a reduction of the inflorescence through a loss of the branches of the second and third order. Also in this species, most inflorescences are narrow and small owing to a lesser development of the lateral branches, and to shorter internodes.

In Aesculus, the terms panicle and thyrse are applicable in designating the inflorescences. According to Rickett (1955), a panicle is a loosely branched inflorescence of which the ultimate units may be of various types. A thyrse is a compact panicle of more or less cylindrical form. These definitions are very broad and general. If they are to be used in manuals and texts to describe specific structures, they should be followed by a qualification as to just what kind of branching and ultimate units are found in the particular taxon being described. In Aesculus the panicle is a principal elongated axis with irregular monopodial branching. The lateral branches are, in this genus, cincinni. The distinction made between the panicle of Billia and that of Aesculus is based upon the difference in the branches-these being lateral panicles in Billia and lateral cincinni in Aesculus.

The basic structure of the lateral cincinnus is illustrated diagrammatically in side view by fig. 4 . A top view of such a cincinnus is shown by Lawrence (1951, p. 63, fig. 3d) although called a "scorpioid cyme" by him. Each cincinnus is subtended by a bract which is either caducous or which may persist through the flowering period.
The sympodial axis is composed of axillary shoots. Each of the axillary shoots is subtended by a small and caducous bracteole, and the terminal extension of each shoot is always limited by a flower or a flower rudiment. It is important in distinguishing this type of lateral axis from a racemose type to understand that in the sympodial axis each bracteole subtends the next sector of the whole "false" axis whereas in the racemose type each bracteole merely subtends the pedicel of one of the lateral flowers. The opposing sterile bracteole, if present, varies in position from a point opposite the fertile and subtending bracteole up to the position of the pedicel joint. When this point of articulation is quite low, the sterile bracteole is usually absent.

The subtending bracteoles, usually larger than the sterile ones, are nearly always present and arise alternately to right and left along the sympodial axis - indicating a cincinnus rather than a drepanium or bostryx. (In a drepanium all subtending bracteoles are on one side of the sympodial axis; in a bostryx they are spiraled around the axis.) In Aesculus, however, the pedicels of the cincinnus are usually bent through an angle of $90^{\circ}$ or less which causes them to be aligned nearly in one plane, or directed upward, and which gives the appearance of a drepanium. The conspicuous downward coiling of the cincinnus in Aesculus is partially due to a slight accentuated growth on one side of the axis, but primarily caused by a decrease in pedicel lengths away from the central axis of the panicle. Since the flowers are nearly in one plane, due to the bending of the pedicels, the true 

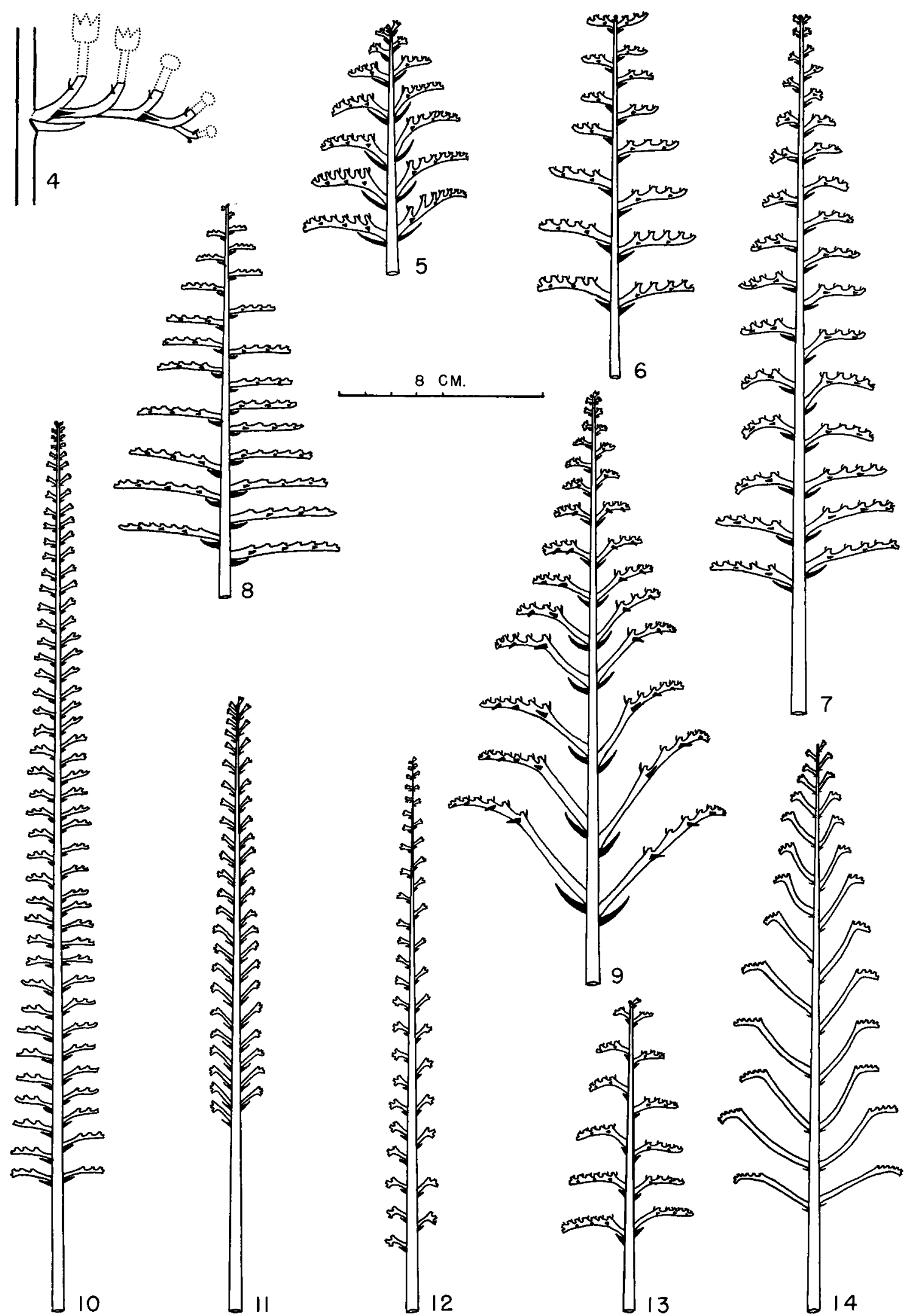
nature of the lateral branch as a cincinnus is indicated only by the alternating lateral bracteoles.

The conspicuous differences among Aesculus inflorescences (fig. 5-14) result from five modifications of the basic form. These modes of specialization occur singly or in combination. Although some of the species have an inflorescence of a characteristic and fairly uniform shape, many of these variations may be found within a single species. For the most part then, the names of the species in fig. 5-14 serve merely as references to the specimens used for the illustrations.

The first of these modifications involves the length of the main axis which is a function of the number of nodes and the lengths of the internodes. There seems to be no close correlation between these two variables so that all four possible combinations may be found-many nodes and short internodes, or few nodes and long internodes, etc. Two obvious extremes in size and shape are the very short and broad type of panicle found frequently in $A$. pavia, A. glabra, and A. sylvatica, and the very long columnar type found most typically in A. parviflora and A. californica. I have noticed that this type of variation may be found also on a single tree or shrub, in which case it is rorrelated with the position and age of the shoot. Vigorous shoots or suckers, arising at the bases of older trees or shrubs, will usually have very long columnar inflorescences. This type of inflorescence would fit the definition of a thyrse. However, since this term, as recently defined by Rickett (1955), implies only a general shape, I see no point in using it for a few inflorescences of Aesculus.

A second modification within the basic form is in the length of the lateral cincinni and the number of nodes in each. Eight flowers appears to be the largest number borne on a single cincinnus of Aesculus and this is at the bottom of the panicle. The presence of only one to three flowers on any cincinnus in a panicle is more or less characteristic of $A$. parryi, A. californica, and A. parviflora. Regularly in Aesculus the distal end of the cincinnus bears one to three abortive flower buds.

The first segment of the lateral cincinnus is elongated at least slightly in most inflorescences. Extreme cases are occasionally found (fig. 9-14) which produce a more or less "hollow" inflorescence, i.e., a panicle in which the flowers occupy the periphery only.

The third modification has to do with the length of the pedicels. No pedicels of Aesculus have been illustrated, except in fig. 4, since the presence of the flowers and pedicels obscures the branching pattern, at least for a two-dimensional illustration.
The pedicel elongates as the flower matures; thus the longest pedicel is normally the one closest to the central axis of the panicle. Resulting from this (as previously mentioned) is a decrease in pedicel length away from the central axis which causes an apparent curvature or downward coiling of the cincinnus, although the sympodial axis itself may be essentially straight.

In addition to the variation in pedicel length on a single cincinnus, one finds that some species are more or less characterized by their pedicel lengths. For example, $A$. parviflora has pedicels usually $1-2$ $\mathrm{cm}$. long while in most of the other species the flowers are nearly sessile or on pedicels $1-5 \mathrm{~mm}$. long.

A fourth modification is in the loss of bracteoles and bracts. The sterile bracteoles are frequently absent. The subtending bracteoles, on the other hand, are nearly always present, and whether they are entirely lost is questionable. A few inflores. cences examined apparently lacked all bracteoles, at least toward the top, but the cincinni in these were reduced to such a point that evidence of the presence of bracteoles or their scars may have been obscured. Neither bract nor bracteole was found on a few inflorescences of $A$. hippocastanum; however, their minute vestiges were probably hidden within the dense, reddish indument covering the axes of the panicle.

The fifth type of modification is in the pattern of branching of the central axis. In Aesculus this does not seem to fit any regular arrangement or phyllotactic fraction. Occasionally an individual inflorescence will have an apparent 2/5 phyllotaxy. In the majority of specimens the branches are whorled, opposite, sub-opposite, or spiral at different levels on the same axis. The diagrammatic illustrations (fig. 5-14) show the branches of only one plane, therefore all nodes are not indicated.

Distribution of PERFECT FLOWERS.-Much has been written concerning the different types of flowers found on an inflorescence of Aesculus (Pax, 1895; Sargent, 1895; Knuth, 1908). Different authors have used a great variety of terms, presumably describing the same situation. Such terms as bisexual, polygamo-monoecious, polygamo-dioecious, andromonoecious, and coenomonoecious have been applied to the Hippocastanaceae, although all species seem to have the same sexual differentiation of the flowers. Most authors do agree that there are two kinds of flowers: (1) staminate, bearing a vestigial pistil, and (2) perfect or bisexual, bearing a fully developed pistil and functional anthers. Andromonoecious would seem best to fit the condition since the plants are func-

Fig. 4-14. Diagrammatic representation of the inflorescences of Aesculas.-Fig. 4. Basic structure of the lateral cincinnus in side view. The pedicels and flowers are indicated by dotted lines. (The scale does not apply here.) - Fig. 5 . $A$. pavia L.-Fig. 6. A. sylvatica Bartr.-Fig. 7. A. pavia L.-Fig. 8. A. octandra Marsh.-Fig. 9. A. pavia L.-Fig. 10. A. parviflora Walt.-Fig. 11. A. californica (Spach) Nutt.-Fig. 12. A. parryi Gray,-Fig. 13. A. glabra Willd.-Fig. 14. A. hippocastanum $\mathrm{L}$. 
tionally monoecious but have both staminate and perfect flowers.

The significance of the different flowers and the protandrous condition in terms of effective crosspollination has been throughly discussed elsewhere (Pax, 1895; Knuth, 1908) and does not need repeating here.

There is much variation in the relative numbers of bisexual and staminate flowers in a single panicle. Coker and Totten (1945) reported that in $A$. sylvatica the perfect flowers were few or rarely entirely absent. In a total of 67 inflorescences and 2,757 flowers they found an average of only 2.7 perfect flowers per inflorescence. Knuth (1908) stated that most of the flowers of $A$. octandra were perfect. Recent dissections of flowers from panicles of A. pavia, A. glabra, and A. parviflora have revealed a paucity of perfect flowers per inflorescence, but lack of sufficient fresh or preserved material prevents my making statistically significant counts like those of Coker and Totten. Granting that the perfect flowers are usually relatively few per panicle, the distribution of these in a single inflorescence becomes the main point of interest.

In Billia, I have noticed from herbarium sheets that the perfect flowers may be at any position in the inflorescence. In Aesculus, however, according to some authors the perfect flowers are present only near the base of the inflorescence (Gray, 1849; Sargent, 1895; Coker and Totten, 1945). On the other hand, Knuth (1908) and Hutchinson (1926) stated that they were variously arranged, and that the arrangement differed among species. Variation in this character is apparent from observations of the infructescences (i.e., fruiting inflorescences) in late summer (fig. 15-20). Although the peduncles and pedicels supporting the mature capsules enlarge greatly, the relative position of the capsules which mature in the panicle remains quite obvious. Also, many of the abortive ovaries remain on the infructescence for some time. Some of the functionally pistillate flowers, however, drop prematurely or fail to set fruit. The presence, then, of the remaining capsules (mature or abortive) does not show the complete distribution of the perfect flowers, but it does show (as in fig. 15-20) that perfect flowers are not limited to the base of the inflorescence or to any particular position of the panicle as once thought.

One similarity among all six infructescences illustrated is that the majority of mature capsules are produced from the perfect flowers which were located near the distal end of the cincinni, or at the periphery of the inflorescence. It would be interesting to know if this is a result of selective pollination.

The illustration of the infructescence of $A$. octandra (fig. 16) substantiates the statement of Knuth (1908) that nearly all flowers in this species were perfect. This large number of capsules in a single infructescence is occasionally found in $A$. sylvatica, $A$. pavia, and $A$. glabra and is not always the condition in $A$. octandra. Distribution of capsules or distribution of perfect flowers is not correlated with species differences.

The long columnar panicles (as in A. parviflora and $A$. californica) very often have capsules scattered throughout the the entire length or occasionally only at the top. Figure 20 of $A$. $\times d u$ pontii (pavia $\times$ sylvatica) shows this situation in which a capsule terminates the infructescence.

Discussion.-CThere has been much speculation as to the origin of inflorescences. Three theories have been proposed postulating the panicle, single terminal flower, or the dichasium as the most primitive type (Lawrence, 1951). Since, in the Hippocastanaceae, we are dealing with the morphology and evolutionary changes within only one basic type of inflorescence (the panicle), it is of no immediate concern what relative position the panicle holds in the phylogeny of all inflorescence types. One may, however, extrapolate from this series of panicles to a primitive leafy branch bearing many dichasial clusters, but this would be only an hypothesis.

In the Hippocastanaceae, my comparative studies indicate a simple reduction series from a diffuse panicle with many lateral paniculate and primarily monopodial branches to a columnar panicle in which the lateral branches are greatly reduced cincinni. I regard, then, the panicle of Billia as primitive and the panicle of Aesculus as having been derived from this, or a somewhat similar ancestral form.

This reduction series is illustrated by tracing the modifications in four morphological characteristics. It is interesting to note in this regard, that many of these modifications appear to have taken place at the top and periphery of the inflorescence first. The bottom nearly always exhibits more primitive characteristics than the top. The central axis and the bottom, therefore, represent the part of the inflorescence which is stable and resistant to morphological modification. The periphery and top appear to be the most plastic and subject to change.

The first quite obvious change has been in the subtending leaf structures-from the typical, palmately compound, vegetative leaf at the base of some Billia inflorescences to the small bracts at the top of these inflorescences and throughout all panicles of Aesculus. The second noticeable change has been from the monopodial and dichasial clusters found in the lateral branches of Billia to the cincinni of Aesculus.

The third modification in this reduction series has affected the scars and subtending bracteoles of the lost members of the primitive dichasial clusters. In Billia the sterile bracteoles are nearly always present and there is usually a conspicuous scar remaining after the abortion and abscission of the member. In Aesculus, however, the sterile 


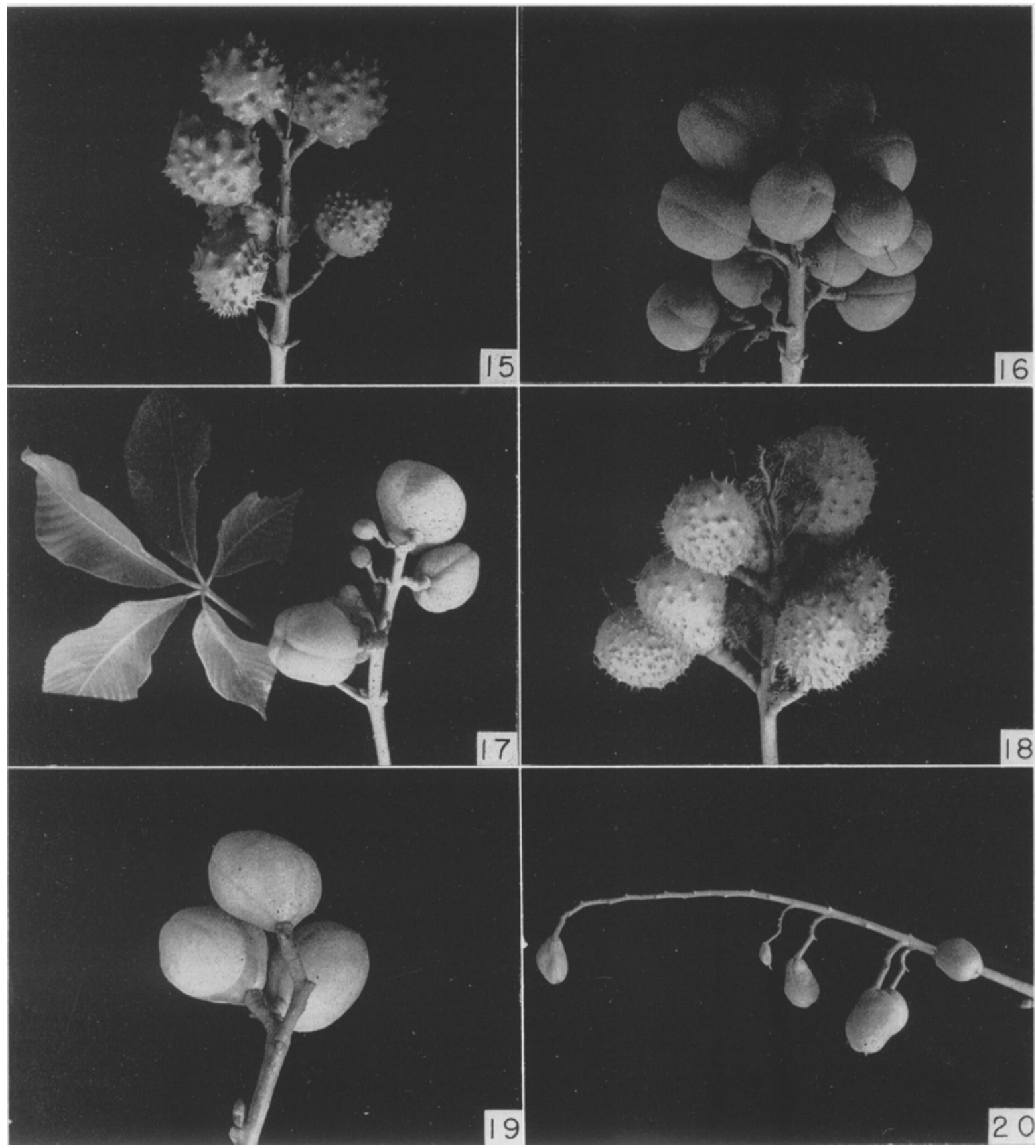

Fig. 15-20. Photographs of infructescences showing variation in position of the mature capsules in Aesculus.-Fig. 15. A. glabra Willd.-Fig. 16. A. octandra Marsh.-Fig. 17. A. sylvatica Bartr.-Fig. 18. A. hippocastanum L..-Fig. 19. A. sylvatica Bartr.-Fig. 20. A. $\times$ dupontii Sarg.

bracteole is frequently absent and there is never a remaining scar. The loss of these structures might be described as being "ontogenetic" in Billia and "phylogenetic" in Aesculus.

A fourth character which has undergone a considerable change in this reduction series is the mode of branching of the central axis. From the exactly opposite and decussate branching in Billia there has been a complete loss of regularity in branching pattern of the central axis in Aesculus. If the main axis of these inflorescences were derived from a leafy branch bearing many dichasial clusters, then Billia is not far removed from this. In Aesculus, on the other hand, the extreme irregularity in phyllotaxy is completely different from the vegetative shoot. 
Since one frequently finds in the literature-texts and manuals-reference to "determinate" and "indeterminate" inflorescences, it seems important to mention this briefly in relation to these inflorescences of the Hippocastanaceae. We now realize that this classification and description of inflorescences on the basis of order of flowering is invalid (Rickett, 1944, 1955). The use, however, of this criterion, dating back to the middle eighteenth century, seems to persist even in the most modern texts.

In Billia and Aesculus it is very difficult to say whether the inflorescence shows a basipetal or acropetal anthesis. In Billia the terminal flower of a dichasial cluster should theoretically mature first, and yet this is seldom so. Within a single lateral cincinnus of Aesculus, which is composed of "determinate" units, the development of flowers should theoretically follow a pattern which, in appearance only, resembles a simple racemose axis of "indeterminate" growth. This expected acropetal anthesis in each lateral cincinnus as well as the entire inflorescence, however, is usually disrupted by the early development of the staminate flowers, i.e., a protandrous condition. It has been noticed in specimens of $A$. parryi and others which I have seen that the capsules frequently mature basipetally. Irrespective of which opens or develops first, the important morphological question is which are initiated first. Lack of ontogenetic study prevents a positive answer to this question.

Within the Hippocastanaceae there appears to be a living representative for many theoretical steps in the evolutionary sequence from the primitive diffuse panicle of Billia to the advanced panicle of Aesculus. Any attempt, however, to correlate this directly with species relationships and origins should wait until considerably more evidence is at hand.

\section{SUMMARY}

In connection with the detailed study of the phylogeny and systematics of the American species of the Hippocastanaceae, analyses of the inflorescence and the distribution of the unisexual and bisexual flowers have been made. The inflorescence of the Latin American genus Billia is a diffuse terminal panicle with a central axis and lateral paniculate branches bearing dichasia at the ends and along the sides; they are in part monopodial. Specialization of this has resulted in reduction of the subtending vegetative leaves to small bracts and the loss of many branches of the second and third order. The inflorescence of Aesculus is a panicle with the principal elongated axis monopodially and irregularly branched and bearing lateral cincinni. The conspicuous variation within the inflorescence of Aesculus results from five types of specialization involving changes in (1) the length of the central axis, (2) the length of the lateral cincinni, (3) the length of the pedicels, (4) the development of bracts and bracteoles, and (5) the branching pattern of the central axis. Although some species of Aesculus have fairly constant inflorescence structure, others are extremely variable. The flowers on a single inflorescence are both staminate and perfect; the plants are therefore andromonoecious. Staminate flowers usually outnumber the perfect ones, although nearly absent in some inflorescences. The perfect flowers, as shown by studies of the mature capsules in the infructescences, may either be grouped at the bottom, or more often, not limited to any particular region of the panicle. Although an evolutionary sequence may be shown for the inflorescences within the family, there can be no attempt to correlate this directly with species relationships and origins until considerably more evidence is at hand.

\footnotetext{
Department of Botany,

UNIVErsity of Michican, Ann Arbor, Michigan
}

\section{LITERATURE CITED}

Coker, W. C., and H. R. Totten. 1945. Trees of the southeastern states. Univ. North Carolina Press. Chapel Hill.

Gray, A. 1849. The genera of the plants of the United States. 2: 203-204. George P. Putnam. New York.

Hutchinson, J. 1926. The families of flowering plants. I. Dicotyledons. Macmillan \& Company. London.

KNUTh, P. 1908. Handbook of flower pollination. (Translation.) 2: 253-255. Clarendon Press. Oxford.

Lawrence, G. H. M. 1951. Taxonomy of vascular plants. The Macmillan Company. New York.
Pax, F. 1895. Hippocastanaceae. In Englir and Prantl, Die natürlichen Pflanzenfamilien. 3 (5) : 273-276.

RicketT, H. W. 1944. The classification of inflorescences. Bot. Rev. 10: 187-231.

1955. Materials for a dictionary of botanical terms -III. Inflorescences. Bull. Torrey Bot. Club 82: 419445.

SArgent, C. S. 1895. The silva of North America. 2: 51-62. Houghton, Mifflin \& Company. New York. 